\title{
Minor involvement of somatic growth in the onset of puberty of Hatano high- and low-avoidance rats
}

\author{
M Shirota, M Sato, K Kojima and R Ohta \\ Safety Testing Laboratory, Hatano Research Institute, Food and Drug Safety Center, 729-5 Ochiai, Hadano, \\ Kanagawa 257-8523, Japan \\ Correspondence should be addressed to M Shirota; Email: shirota.m@fdsc.or.jp
}

\begin{abstract}
The present study was planned to examine the effects of somatic growth on the determination of timing of puberty using Hatano high- and low-avoidance rats (HAAs and LAAs); the rats were genetically selected from Sprague-Dawley (SD) rats for good or poor performance in a two-way active avoidance-learning test. Since these two lines were found to have different characteristics, such as body weight at birth, maternal care and timing of male puberty, the present study characterized female puberty in Hatano rats and then compared postnatal growth and timing of puberty between the two lines of rats when they were nursed by foster SD dams. When nursed under biological dams, HAAs became heavier, exhibited vaginal opening at a younger age and first ovulation was accompanied by more oocytes than LAAs. In all of the HAAs, but none of the LAAs, ovulation was induced by a single s.c. injection of $5 \mathrm{IU}$ equine chorionic gonadotropin (eCG) on day 22 after birth. An additional treatment with $10 \mathrm{IU}$ human CG revealed that, in the ovaries of LAAs, a small number of follicles had developed to an ovulable stage as a result of the treatment. The fostering improved somatic growth, and weights of LAAs were sustained at a heavier level than those of fostered HAAs. The fostering, however, did not eliminate the line difference in the timing of puberty of both sexes; it did accelerate the vaginal opening of LAAs but not the balanopreputial separation. Thus, there is a phenotypic difference in the timing of female puberty in Hatano rats exhibiting a different timing of ovarian development in response to gonadotropin. The present study indicates that postnatal somatic growth is not the predominant determinant in the onset of puberty in Hatano rats.

Reproduction (2004) 127 389-395
\end{abstract}

\section{Introduction}

Somatic growth, including nutrition, until puberty is one of the factors that modify the timing of puberty (Ojeda \& Urbanski 1994). Intra-uterine growth retardation caused by uterine artery ligation was found to delay the puberty of male and female rats, and food restriction caused by litter enlargement was found to delay male puberty (Engelbregt et al. 2000). Reduction in protein intake without altering daily total caloric intake delays puberty in male and female rats (Ramaley 1981). Food deprivation during the prepubertal period inhibits pulsatile luteinizing hormone (LH) release of immature female rats, and inhibits the first ovulation until 3 days after the resumption of feeding ad libitum (Bronson 1986). All these experiments indicate the involvement of nutrition or bodily growth in the timing of puberty, however, there has been little examination of the hypothesis under physiological conditions.
Hatano rats have been selectively inbred over 30 generations from Sprague-Dawley (SD) rats; they have been inbred for rapid acquisition of a conditioned avoidance response in the shuttlebox test (high-avoidance animals (HAAs)) and for a failure to acquire this response (lowavoidance animals (LAAs)) (Ohta et al. 1995). The shuttlebox is a device used for evaluating the effects of chemicals in pharmacological and toxicological studies, and for testing learning behavior of animals. Using this device, the two-way active avoidance test, known as the shuttlebox avoidance test, assesses the acquisition of the ability to flee to the safe chamber after the onset of the conditioned stimulus. This test tended to produce high variability in the data from a heterogeneous animal population; therefore, in 1985, Hatano rats were developed in our institute to obtain uniform data and to facilitate the evaluation of effects of exogenous chemical substances in behavioral tests (Ohta et al. 1995, 1997, 2000). Although Hatano rats were genetically selected only on the basis of 
their divergent performance in the shuttlebox avoidance test, unexpected phenotypic differences have also been observed; for example, reproductive, developmental and endocrinological characteristics and stress responses (Ohta et al. 1998, 1999, 2000, 2002a,b, Asai et al. 2002, Sato et al. 2002a,b,c). Among these characteristics, the line differences in body weight at birth (Ohta et al. 1998) and maternal care (Ohta et al. 2002b) might be suitable characteristics for model animals used to study the effects of somatic growth on the timing of puberty under physiological conditions, since their postnatal growth can be modified by nursing dams (Ohta et al. 1998). Furthermore, the fact that balanopreputial separation, one of the indices of male puberty, occurs at a younger age in HAAs than in LAAs (Sato et al. 2002c) leads to the hypotheses that the line difference is also observed in the timing of female puberty and that somatic growth determines the timing of puberty under physiological conditions.

To investigate the hypotheses further, the present study characterized the female puberty of Hatano rats, including timing of vaginal opening, first ovulation and the development of an ovulatory response to a single injection of equine chorionic gonadotropin (eCG); we then compared postnatal growth and timing of puberty between the two lines of rats which had been nursed by foster SD dams. The present comparative studies between these two inbred strains of rats, developed under the same housing and breeding conditions, may provide an answer to the question of whether or not somatic growth regulates the onset of puberty.

\section{Materials and Methods}

\section{Animals}

All procedures described here were approved by the local ethics committee (the Committee on Animal Care and Use in the Hatano Research Institute of the Food and Drug Safety Center). In the present study we used female HAAs and LAAs from over the 35th generation to have been bred at the Hatano Research Institute of the Drug and Food Safety Center. For two separate fostering experiments, observing both female and male puberty, adult females (two of each line per experiment) were mated with adult males of the same line overnight in order to obtain pups for the studies. Six and two pregnant SD rats [Crj:CD(SD)IGS] (for female and male puberty investigations respectively) were purchased as foster dams from Charles River Japan (Atsugi, Kanagawa) at gestational day 14. These animals were maintained under a $12 \mathrm{~h}$ light: $12 \mathrm{~h}$ darkness cycle (lights on 0700-1900 h) in an animal husbandry facility in which standard temperature and humidity were controlled at $22-25^{\circ} \mathrm{C}$ and $40-60 \%$ respectively. The animals were supplied with laboratory rodent chow (CE-2, Clea Japan Inc., Tokyo) and tap water ad libitum.

\section{Hormones}

Stock solutions of eCG (2830 IU/mg, Sigma) and human chorionic gonadotropin (hCG) (1160 IU/mg, Sankyo Zoki Co., Tokyo) were prepared by dissolving the hormones in sterilized saline to 50 and $100 \mathrm{IU} / \mathrm{ml}$ respectively. These stock solutions were stored at $-20{ }^{\circ} \mathrm{C}$, and were diluted with sterilized saline to 25 or $50 \mathrm{IU} / \mathrm{ml}$ before use.

\section{Observation of female puberty of Hatano rats nursed by biological dams}

Forty-eight LAAs and 58 HAAs, reared by their biological dams (eight pups per dam), were examined daily for external genitalia from day 28 after birth to the day on which vaginal opening was found. Another seven females from each line were weighed at weaning (on day 21 after birth) and were killed by ether inhalation on the day of vaginal opening to evaluate the first ovulation. The numbers of oocytes were counted in the animals in which freshly ovulated oocytes were found in the ampullae by the method of Burdick and Whitney (Burdick \& Whitney 1941). The masses of the ovaries and uterus were determined in these animals.

\section{Induction of ovulation in immature HAAs and LAAs}

Thirty-seven and 35 immature female HAAs and LAAs respectively were examined for responses to a single s.c. administration of $5 \mathrm{IU}$ eCG at $0900 \mathrm{~h}$ on one of days 2026 after birth. Some of the LAAs were injected with hCG at $56 \mathrm{~h}$ after eCG treatment on day 22 after birth; this was done in order to examine the number of follicles that had developed, as a result of the eCG treatment, to a stage at which the follicles could ovulate in response to an exogenous ovulatory stimulus. All of these animals were killed by ether inhalation at more than $72 \mathrm{~h}$ after the eCG treatment and were examined to assess whether ovulation had been induced. The masses of the ovaries and uterus in these animals were determined.

\section{Fostering under SD dams}

All of the pregnant SD and Hatano rats were allowed to deliver spontaneously. The HAA and LAA dams were allowed to nurse their own offspring for 1 day, whereas the SD dams were allowed to nurse their own offspring for more than 1 day while waiting for the HAA and LAA pups to reach day 1 after birth. On day 1 after birth, neonates from HAA and LAA dams were weighed and identified as belonging to a given line by a tattoo on the forelimb. They were assigned to six SD dams for observation of female puberty and two SD dams for observation of male puberty; these SD dams had had their own offspring taken away. Each SD dam nursed eight foster pups consisting of one to three females and males of each line. Litter weight was measured on days 4, 7 and 14 after birth and compared according to line and sex. On day 21 after birth, the foster pups were weighed individually and 
weaned. In the fostering study to observe female puberty, individual female body weight was also measured on day 28 after birth, while male littermates were killed at weaning. On the day of vaginal opening, the offspring were weighed and killed by ether inhalation, and were examined for ovulation. The masses of the ovaries and uterus were determined. In the fostering study to observe male puberty, individual male body weight was also measured weekly until 35 days after birth and on the day of balanopreputial separation.

\section{Statistical analysis}

All data are expressed as mean \pm S.E.M. for each line. The analysis of variance was performed by $F$-test. Student's $t$ test was conducted when the variance was homogenous, while the Aspin-Welch $t$-test was used when it was not homogenous. A $P$ value of less than 0.05 was taken as the level indicating statistical significance.

\section{Results}

\section{Timing of female puberty of Hatano rats nursed by biological dams}

Age at vaginal opening of Hatano rats is illustrated in Fig. 1. In the HAAs, vaginal opening occurred during days $30-36$ after birth, and the mean age ( \pm S.E.M.) at vaginal opening was $32.8 \pm 0.2$ days after birth $(n=58)$. In contrast, none of the LAAs showed vaginal opening until day 33 after birth. They showed vaginal opening during days 33-39 after birth and the mean age at vaginal opening was $36.4 \pm 0.2$ days after birth $(n=48)$. Thus, there was a significant difference in the age at vaginal opening between the lines $(P<0.0001)$. The body weight at vaginal opening in the HAAs $(98.7 \pm 0.9 \mathrm{~g})$ was significantly

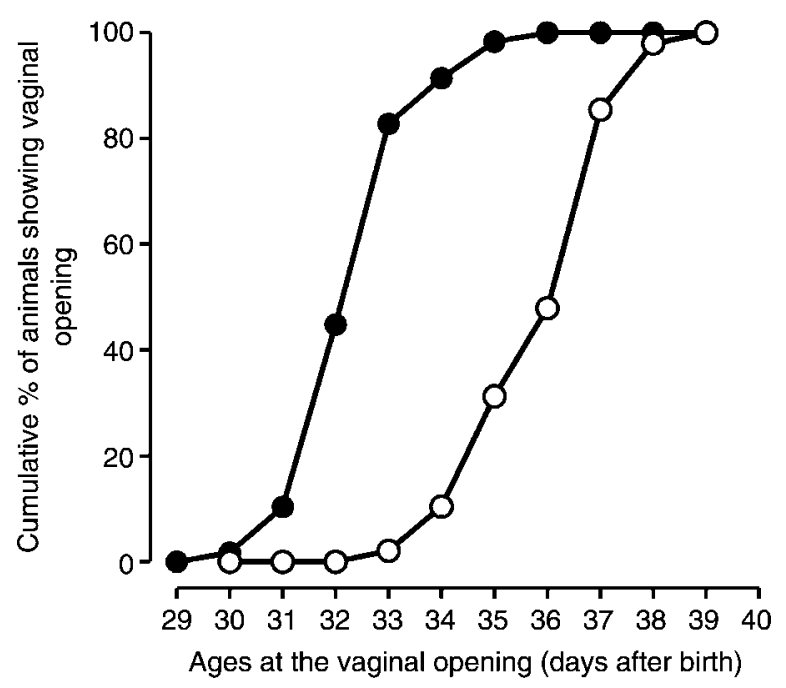

Figure 1 Occurrence of vaginal opening in HAAs $(\bullet)$ and LAAs $(O)$. The vertical axis shows the cumulative percentage of animals in which vaginal opening was found in each line of animals examined (58 HAAs and 48 LAAs); the horizontal axis indicates age in days. lower $(P<0.0001)$ than that in the LAAs $(105.9 \pm 1.3 \mathrm{~g})$. Although there is remarkably divergent distribution in the occurrence of vaginal opening in Hatano rats, the ages at vaginal opening were within the range of our background data for SD rats (days 28-40 after birth in 78 observations).

\section{Weaning weight and the first ovulation in Hatano rats nursed by biological dams}

With the exception of one HAA female that had ovulated before vaginal opening, the first ovulation accompanied vaginal opening in all of the HAAs and LAAs in this study (Table 1). HAAs, a heavier line at weaning, showed first ovulation at a younger age than LAAs, and the number of oocytes shed was significantly larger than that in the LAAs. Despite the lighter body weight at first ovulation of the HAAs, their uterine masses were significantly heavier than those of the LAAs.

\section{Induction of ovulation in immature Hatano rats}

A single s.c. injection of an appropriate amount of eCG, when given to immature rats, can induce ovulation 3 days later; the treatment induces follicles to develop to ovulable stage and to secrete sufficient amounts of oestradiol$17 \beta$ to trigger gonadotropin discharge. Treatment on day 21 after birth onward induced ovulation in HAAs, and treatment on day 22 after birth induced ovulation in all of the treated HAAs (Table 2). In contrast, such treatment before day 22 after birth failed to induce ovulation in LAAs and such treatment on day 26 after birth induced ovulation in all of the treated LAAs. In order to examine the number of ovulable follicles that had developed as a result of the treatment on day 22 after birth in the ovary of LAAs, $10 \mathrm{IU}$ hCG was additionally injected at $56 \mathrm{~h}$ after the eCG treatment. The treatment induced ovulation in all LAAs, however, the number of oocytes shed was smaller

Table 1 Body weight at weaning on day 21 after birth and the first ovulation in HAAs and LAAs.

\begin{tabular}{lccc}
\hline Lines & HAAs & LAAs & $\boldsymbol{P}^{*}$ \\
\hline $\begin{array}{l}\text { Number of animals examined } \\
\text { Body weight on day 21 }\end{array}$ & 7 & 7 & \\
$\begin{array}{l}\text { after birth (g) } \\
\text { Age at vaginal opening } \\
\quad \text { days after birth) }\end{array}$ & $31.5 \pm 1.1$ & $31.7 \pm 0.8$ & $<0.0001$ \\
$\begin{array}{l}\text { Body weight at vaginal } \\
\quad \text { opening (g) }\end{array}$ & $93.8 \pm 1.6$ & $101.5 \pm 2.1$ & $<0.05$ \\
$\begin{array}{l}\text { Number of animals found } \\
\quad \text { ith fresh oocytes }\end{array}$ & 6 & 7 & \\
$\begin{array}{l}\text { Body weight (g) } \\
\text { Number of oocytes shed }\end{array}$ & $93.4 \pm 1.8$ & $101.5 \pm 2.1$ & $<0.05$ \\
$\begin{array}{l}\text { Ovarian mass (mg) } \\
\text { Uterine mass (mg) }\end{array}$ & $27.0 \pm 0.3$ & $12.4 \pm 0.4$ & $<0.01$ \\
& $190.1 \pm 4.9$ & $174.2 \pm 3.8$ & $<0.05$ \\
\hline
\end{tabular}

* Significant difference between HAAs and LAAs nursed by biological dams. 
Table 2 Induced ovulation to various ages of immature HAAs and LAAs by subcutaneous injection of 5 IU eCG or 5 IU eCG and 10 IU hCG.

\begin{tabular}{|c|c|c|c|c|c|c|c|c|}
\hline \multicolumn{2}{|c|}{$\begin{array}{l}\text { Age } \\
\text { treatment* }\end{array}$} & \multirow{2}{*}{$\begin{array}{l}\text { Body weight at } \\
\text { eCG treatment }(\mathrm{g})\end{array}$} & \multicolumn{2}{|c|}{ Induced ovulation } & \multicolumn{2}{|c|}{ Ovarian mass (mg) } & \multicolumn{2}{|c|}{ Uterine mass (mg) } \\
\hline eCG & hCG & & Ovulated/not ovulated & Oocytes shed $^{+}$ & Ovulated & Not ovulated & Ovulated & Not ovulated \\
\hline \multicolumn{9}{|l|}{ HAAs } \\
\hline 20 & - & $35.7 \pm 1.6$ & $0 / 7$ & - & - & $13.3 \pm 1.3$ & - & $143.7 \pm 10.6$ \\
\hline 21 & - & $40.9 \pm 1.1$ & $3 / 5$ & $5.0 \pm 1.5$ & $19.9 \pm 2.5$ & $14.9 \pm 0.6$ & $144.9 \pm 6.2$ & $164.0 \pm 5.0$ \\
\hline 22 & - & $42.5 \pm 1.4$ & $6 / 0$ & $8.8 \pm 1.1$ & $20.3 \pm 1.4$ & - & $129.0 \pm 4.6$ & - \\
\hline 23 & - & $44.0 \pm 0.7$ & $3 / 0$ & $8.0 \pm 1.0$ & $20.9 \pm 1.7$ & - & $137.2 \pm 5.6$ & - \\
\hline 24 & - & $48.9 \pm 2.6$ & $5 / 0$ & $10.0 \pm 0.9$ & $23.8 \pm 1.6$ & - & $129.5 \pm 4.9$ & - \\
\hline \multicolumn{9}{|l|}{ LAAs } \\
\hline 21 & - & $37.0 \pm 1.1$ & $0 / 5$ & - & - & $21.7 \pm 1.2$ & - & $149.5 \pm 4.7$ \\
\hline 22 & - & $39.3 \pm 1.2$ & $0 / 6$ & - & - & $20.5 \pm 0.5$ & - & $154.3 \pm 2.0$ \\
\hline 23 & - & $46.0 \pm 0.8$ & $4 / 2$ & $9.8 \pm 1.5$ & $23.9 \pm 0.9$ & $21.3 \pm 2.2$ & $115.2 \pm 2.9$ & 141.0 \\
\hline 24 & - & $46.9 \pm 1.7$ & $5 / 2$ & $11.0 \pm 0.9$ & $26.8 \pm 0.7$ & 18.6 & $112.0 \pm 3.6$ & 150.5 \\
\hline 25 & - & $50.6 \pm 1.8$ & $3 / 2$ & $12.3 \pm 0.7$ & $25.3 \pm 1.5$ & 22.0 & $123.1 \pm 5.1$ & 158.6 \\
\hline 26 & - & $54.2 \pm 1.0$ & $5 / 0$ & $11.0 \pm 0.3$ & $27.5 \pm 1.4$ & - & $107.6 \pm 3.8$ & - \\
\hline 22 & 24 & $34.8 \pm 1.2$ & $5 / 0$ & $3.8 \pm 1.0$ & $21.4 \pm 1.4$ & - & $108.3 \pm 6.6$ & - \\
\hline
\end{tabular}

eCG was administered at 09:00 $\mathrm{h}$ and ovulation was examined at more than $72 \mathrm{~h}$ after eCG-treatment. $\mathrm{hCG}$ was administered $56 \mathrm{~h}$ after eCG administration.

* Days after birth.

${ }^{+}$Values from the rats found to be ovulating.

than that counted at the ovulation in HAAs induced by eCG alone (on day 22 after birth).

\section{Effects of fostering on the somatic growth and puberty of Hatano rats}

As shown in Fig. 2, LAAs were heavier than HAAs on the initial day of fostering. The difference between the lines was maintained during the whole fostering period. Whereas statistical differences between the lines were found only in females on days 4, 7 and 21 after birth, the fostering greatly improved the somatic growth of both lines of pups because of the better nursing of the foster SD dams than that of both lines of the biological dams (Table 1). Body weights of foster pups for observation of male puberty showed similar changes to those shown in Fig. 2 (data not shown).

Post-weaning weight and female puberty of fostered Hatano rats are summarized in Table 3. Despite the heavier post-weaning weights of fostered LAAs compared with fostered HAAs, the mean age at vaginal opening in fostered HAAs was significantly lower than that in fostered LAAs. When compared with vaginal opening in LAAs nursed by biological dams (Table 1), fostering advanced the vaginal opening of LAAs by more than 2 days. Fostered females were examined for ovulation on the day of vaginal opening. Three and ten of the fostered HAAs and LAAs respectively were found to have corpus luteum in their ovaries with old oocytes in their oviducts; these animals were therefore considered to have ovulated 1 day before. Based on these findings, the inferred age at first ovulation in fostered HAAs (31.7 \pm 0.2 days after birth) was younger than that in fostered LAAs (33.2 \pm 0.4 days after birth). No significant differences were found between fostered HAAs and LAAs in the numbers of corpora lutea or oocytes shed.
Post-weaning weights and the timing of balanopreputial separation of fostered male Hatano rats are shown in Table 4. Post-weaning weights of fostered LAAs were similar to those of age-matched fostered HAAs; however, balanopreputial separation of fostered LAAs was found at a significantly older age than in the fostered HAAs.
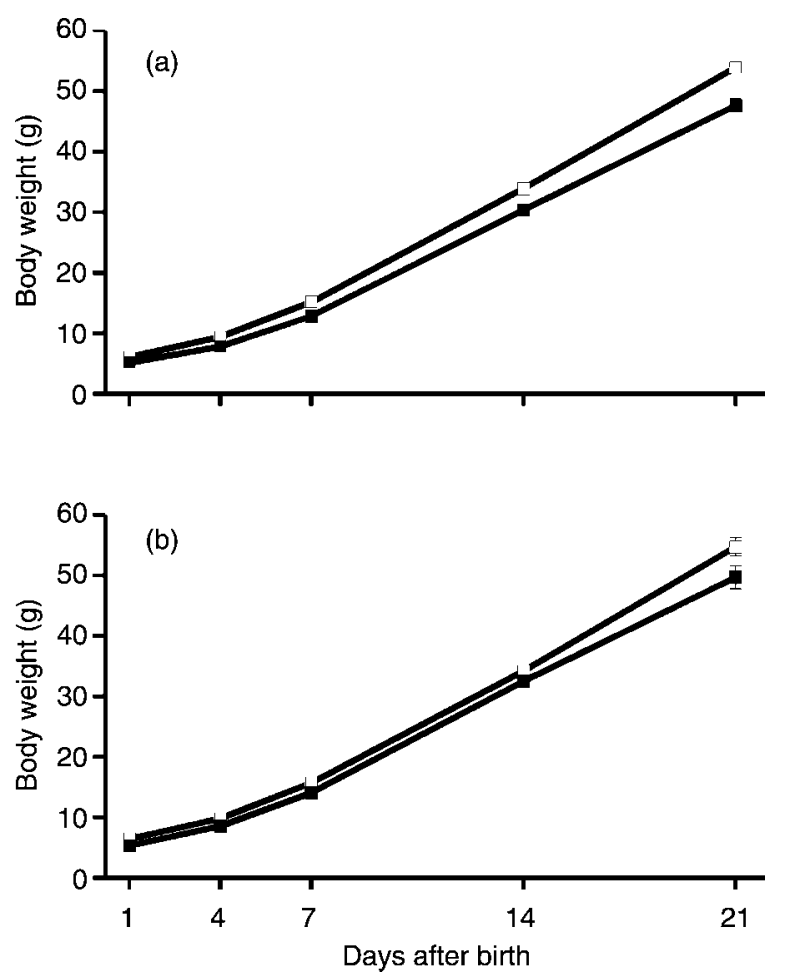

Figure 2 Changes in body weight of fostered HAAs (घ) and LAAs ( $\square$ ) during the period of nursing by SD dams. Body weights of females (a) and their male foster-mates (b) are shown. Each square represents the mean pup weight of six litters that was calculated from litter weight. Vertical bars represent S.E.M. 
Table 3 Post-weaning weight and female puberty of HAAs and LAAs fostered by SD dams from days 1 to 21 after birth.

\begin{tabular}{|c|c|c|c|}
\hline & Fostered HAAs & Fostered LAAs & $P$ values* \\
\hline \multicolumn{4}{|l|}{ Post-weaning weight } \\
\hline Day 28 after birth (g) & $78.1 \pm 3.1(12)$ & $83.8 \pm 1.2(17)$ & $\geq 0.05$ \\
\hline \multicolumn{4}{|l|}{ Vaginal opening } \\
\hline Age (days after birth) & $31.9 \pm 0.3(12)$ & $33.8 \pm 0.4(17)$ & $<0.01$ \\
\hline Body weight $(\mathrm{g})$ & $101.0 \pm 2.9(12)$ & $115.0 \pm 2.2(17)$ & $<0.01$ \\
\hline \multicolumn{4}{|c|}{ Necropsy at the vaginal opening } \\
\hline Number of corpus luteum & $13.2 \pm 0.4(12)$ & $12.6 \pm 0.2(17)$ & $\geq 0.05$ \\
\hline Number of oocytes shed & $12.7 \pm 0.5(9)$ & $12.7 \pm 0.3(7)$ & $\geq 0.05$ \\
\hline Ovarian mass (mg) & $27.1 \pm 0.8(9)$ & $26.0 \pm 1.5(7)$ & $\geq 0.05$ \\
\hline Uterine mass (mg) & $196.5 \pm 5.0(9)$ & $182.5 \pm 5.3(7)$ & $\geq 0.05$ \\
\hline
\end{tabular}

* Significant difference between fostered HAAs and LAAs. Data are expressed as mean \pm S.E.M. of each animal, and parentheses indicate the number of animals.

Table 4 Post-weaning weight and timing of male puberty in HAAs and LAAs fostered by SD dams from days 1 to 21 after birth.

\begin{tabular}{lcrl}
\hline & $\begin{array}{c}\text { Fostered } \\
\text { HAAs }\end{array}$ & \multicolumn{1}{c}{$\begin{array}{c}\text { Fostered } \\
\text { LAAs }\end{array}$} & P values* \\
\hline $\begin{array}{l}\text { Number of animals examined } \\
\text { Post-weaning weights }\end{array}$ & 6 & 4 & \\
$\quad \begin{array}{lrll}\text { Day 28 after birth } \\
\text { Day 35 after birth }\end{array}$ & $86.4 \pm 2.9$ & $84.2 \pm 2.2$ & $\geq 0.05$ \\
$\begin{array}{l}\text { Balanopreputial separation } \\
\text { Age (days after birth) }\end{array}$ & $141.7 \pm 4.2$ & $136.1 \pm 5.4$ & $\geq 0.05$ \\
$\quad$ Body weight (g) & $41.2 \pm 0.4$ & $47.0 \pm 0.0$ & $<0.0001$ \\
\hline
\end{tabular}

* Significant difference between fostered HAAs and LAAs. Data are expressed as mean \pm S.E.M. of each animal.

\section{Discussion}

The present study revealed that there is a line difference in the timing of female puberty between two lines of Hatano rats. As found in male Hatano rats (Sato et al. 2002c), HAAs, which were born with a lighter weight but became heavier under biological dams, attained puberty at a younger age than LAAs. Fostering under SD dams gave an identical nursing condition to both lines of pups, and the fostered LAAs kept their body weight at a higher level than the fostered HAAs. The improvement of the nursing condition, however, did not eliminate the line difference in the timing of puberty in both sexes. These results indicate that postnatal body weight increase is not the primary determinant of the timing of puberty in Hatano rats.

While the fostering did not eliminate the line differences in timing of puberty, it accelerated puberty of female LAAs. Nutritional disruption has been reported to alter profiles of gonadotropin secretion in females by affecting neurosecretory activity of the hypothalamus in several mammalian species, including rats (Cagampang et al. 1990, Moriyama et al. 2003), hamster (Morin 1986), lambs (Foster \& Olster 1985) and human (Loucks \& Verdun 1998). Since the amount of milk secretion by LAA dams is smaller than that of HAA dams (Ohta et al. 2002b) and probably smaller than that of SD dams, LAA pups under their biological dams might be maintained in a slightly poor nutritional condition and this could affect neurosecretory activity. In contrast to female LAAs, fostering did not affect the timing of puberty in male LAAs, although it was reported that the nutritional disruption affected pulsatile LH release in male rats (Badger et al. 1985, Tsukamura et al. 2000). Causes of the different effects of the fostering on the timing of puberty in male and female LAAs might be explained by a difference in the duration of the period from weaning to the occurrence of puberty; however, the present results demonstrate a sex difference in the effects of the fostering on the timing of puberty.

Fostering improved the growth of fostered HAAs, but differences in the age at vaginal opening between fostered and non-fostered HAAs were small. The age of vaginal opening of fostered HAAs was statistically different $(P<0.05)$ from that of the non-fostered HAAs shown in Fig. 1, but was not different from that of the non-fostered HAAs shown in Table 1. From these results, improvement of body weight increase was not judged to advance the timing of puberty in HAAs. Considering the acceleration of female puberty in LAA females by the fostering, these results suggest that the timing of female puberty, which has already been determined, could only be modified under poor nutritional conditions. A recent review (Mann \& Plant 2002) has pointed out that leptin, an adipocyte-secreting peptide hormone, plays a permissive rather than a causal role in timing of puberty. While the present study did not compare circulating levels of leptin between the fostered and non-fostered LAAs, changes in such substances that inform the hypothalamus of nutritional conditions may be involved in the acceleration of female puberty in the fostered LAAs.

Treatment with a single s.c. injection of eCG to agematched female Hatano rats revealed that there is a line difference in the timing of completion of ovarian maturation to develop follicles. Since completion of ovarian maturation is essential for preovulatory gonadotropin discharge (reviewed by Ojeda \& Urbanski 1994), the line difference in the timing of female puberty could be attributed to the difference in the timing of ovarian maturation. While the number of ovulable follicles, which have developed as a result of the treatment on day 22 after birth, 
was smaller in LAAs than in HAAs, those in LAAs became comparable to HAAs on day 23 after birth onward. From these results, a slightly later development of follicles to respond to gonadotropin may play a role in the difference in the timing of female puberty between the lines. In male Hatano rats, circulating follicle-stimulating hormone ( $\mathrm{FSH}$ ) levels were higher in HAAs than LAAs as early as day 21 after birth (Sato et al. 2002c). Since FSH promotes FSH receptor in the granulosa cells in vitro (Tilly et al. 1992), endocrinological profiles during early life could be different between both lines of females.

The number of oocytes shed at first ovulation in HAAs was significantly larger than that of LAAs. A similar difference was also observed between adult cyclic HAAs and LAAs (Asai et al. 2002). Thus, HAAs ovulate more oocytes than LAAs from the first estrus. Size-fractionated comparisons of ovarian follicles between adult HAAs and LAAs revealed that a greater number of large antral follicles had developed in HAA ovaries by noon of the day of proestrus as compared with LAAs (Asai et al. 2002). In contrast, no differences in the numbers of oocytes shed at the induced ovulation were found between immature HAAs and LAAs, and the number in LAAs was comparable to that counted at the first ovulation. These results suggest that more follicles may have developed in HAA ovaries during the post-weaning prepubertal period than in LAA ovaries.

It is uncertain whether the line difference in the onset of puberty is caused by the fetal environment or by genetic differences. A report that exposure to glucocorticoids in utero alters the onset of puberty in males and females (Smith \& Waddell 2000) suggests a potent involvement of the fetal environment in the determination of puberty. Although there is a line difference in adrenal size between adult LAAs and HAAs (Ohta et al. 1999), circulating corticosterone levels are generally comparable between the lines even under stressed conditions (Ohta et al. 2002a). Furthermore, no line difference was observed in the circulating corticosterone levels at the terminal period of pregnancy (Ohta et al. 2002b). It seems that maternal corticosterone itself may not be involved in the onset of puberty in Hatano rats. Roman high-avoidance and lowavoidance (RHA and RLA) rats, which have been selected from the Wistar strain for a similar character to Hatano rats (Bignami 1965), also have a line difference in the onset of puberty (Rivest 1991). It is obvious, however, that learning ability itself is not linked with the timing of puberty, since the low-avoidance line (RLA) attains female puberty at a younger age than the high-avoidance line (RHA). Comparisons of the substantial similarities and differences between Hatano and Roman rats may suggest novel mechanisms for determining the onset of puberty in the rat.

In conclusion, the phenotypic difference of Hatano rats in the onset of puberty is found not only in males but also in females, and postnatal somatic growth is not the predominant determinant in the onset of puberty of Hatano rats.
Hatano rats are not only good tools for evaluating the effects of chemicals on learning behavior, but will also be good models for elucidating the common mechanisms underlying the onset of puberty in both sexes.

\section{Acknowledgements}

This study was partly supported by Grant-in-Aid Scientific Research (11839003 and 14360190) from the Ministry of Education, Science, Sports and Culture of Japan.

\section{References}

Asai S, Ohta R, Shirota M, Sato M, Watanabe G \& Taya K 2002 Reproductive endocrinology in Hatano high- and low-avoidance rats during the estrous cycle. Endocrine 18 161-166.

Badger TM, Lynch EA \& Fox PH 1985 Effects of fasting on luteinizing hormone dynamics in the male rat. Journal of Nutrition 115 788-797.

Bignami G 1965 Selection for high rates and slow rates of avoidance conditioning in the rat. Animal Behavior 13 221-227.

Bronson FH 1986 Food-restricted, prepubertal, female rats: rapid recovery of luteinizing hormone pulsing with excess food, and full recovery of pubertal development with gonadotropin-releasing hormone. Endocrinology 118 2483-2487.

Burdick HO \& Whitney R 1941 Ovulation induced in mice by single injection of follutein or untreated human pregnancy urine. American Journal of Physiology 132 405-410.

Cagampang FR, Maeda K, Yokoyama A \& Ota K 1990 Effect of food deprivation on the pulsatile $\mathrm{LH}$ release in the cycling and ovariectomized female rat. Hormone and Metabolic Research 22 269-272.

Engelbregt MJ, Houdijk MECAM, Popp-Snijders C \& Delemarre-van de Waal HA 2000 The effects of intra-uterine growth retardation and postnatal undernutrition on onset of puberty in male and female rats. Pediatric Research 48 803-807.

Foster DL \& Olster DH 1985 Effect of restricted nutrition on puberty in the lamb: patterns of tonic luteinizing hormone $(\mathrm{LH})$ secretion and competency of the LH surge system. Endocrinology 116 $375-381$.

Loucks AB \& Verdun M 1998 Slow restoration of LH pulsatility by refeeding in energetically disrupted women. American Journal of Physiology 275 R1218-R1226.

Mann DR \& Plant TM 2002 Leptin and pubertal development. Seminars in Reproductive Medicine 20 93-102.

Morin LP 1986 Environment and hamster reproduction: responses to phase-specific starvation during estrous cycle. American Journal of Physiology 251 R663-R669.

Moriyama R, Reyes BAS, Tsukamura H \& Maeda K 2003 Glucoprivation-induced Fos expression in the hypothalamus and medulla oblongata in female rats. Journal of Reproduction and Development 49 151-157.

Ohta R, Matsumoto A, Hashimoto Y, Nagao T \& Mizutani M 1995 Behavioral characteristics of rats selectively bred for high and low avoidance shuttlebox response. Congenital Anomalies $\mathbf{3 5}$ $223-229$.

Ohta R, Matsumoto A, Hashimoto Y, Nagao T \& Mizutani M 1997 Behavioral characteristics of microencephalic rats in high and low shuttlebox avoidance lines. Neurotoxicology and Teratology 19 $157-162$.

Ohta R, Matsumoto A, Nagao T \& Mizutani M 1998 Comparative study of behavioral development between high and low shuttlebox avoidance rats. Physiology and Behavior 63 545-551.

Ohta R, Shirota M, Adachi T, Tohei A \& Taya K 1999 Plasma ACTH levels during early, two-way avoidance acquisition in high- and low-avoidance rats. Behavior Genetics 29 137-144. 
Ohta R, Matsumoto A, Sato M, Shirota M, Nagao T, Tohei A \& Taya K 2000 Postnatal behavior in Hatano high- and low-avoidance rats following prenatal exposure to low-dose methylazoxymethanol. Neurotoxicology and Teratology 22 405-413.

Ohta R, Fujikawa T, Tanaka M, Asai S, Taya K, Tago K \& Shirota M 2002a A different response to acute stress of Hatano high- and low-avoidance rats: relationship with gastric erosions and the paraventricular prolactin receptor. Abstracts of the XIVth International Workshop on Genetic System In the Rat, P-45. Kyoto, Japan.

Ohta R, Shirota M, Tohei A \& Taya K 2002b Maternal behavior, milk ejection, and plasma hormones in Hatano high- and low-avoidance rats. Hormones and Behavior 42 116-125.

Ojeda R \& Urbanski HF 1994 Puberty in the rat. In The Physiology of Reproduction, 2nd edn, vol 2, pp 363-409. Eds E Knobil \& JD Neil. New York: Raven Press.

Ramaley JA 1981 Puberty onset in males and females fed a high fat diet. Proceedings of the Society for Experimental Biology and Medicine $166294-296$.

Rivest RW 1991 Sexual maturation in female rats: hereditary, development and environmental aspects. Experimentia 47 1026-1038.

Sato M, Ohta R, Kojima K \& Shirota M 2002a Differences in sperm motion between high- and low-shuttlebox avoidance rats (Hatano strains). Journal of Andrology 23 250-258.
Sato M, Ohta R, Kojima K \& Shirota M 2002b Strain differences in the spontaneous incidence of sperm morphological abnormalities in Hatano rats. Journal of Veterinary Medical Sciences 64 389-390.

Sato M, Ohta R, Kojima K, Shirota M, Koibuchi H, Asai S, Watanabe G \& Taya K 2002c A comparative study of puberty, and plasma gonadotropin and testicular hormone levels in two inbred strains of Hatano rats. Journal of Reproduction and Development $48111-119$.

Smith JT \& Waddell BJ 2000 Increased fetal glucocorticoid exposure delays puberty onset in postnatal life. Endocrinology 141 $2422-2428$.

Tilly JL, LaPolt PS \& Hsueh AJ 1992 Hormonal regulation of folliclestimulating hormone receptor messenger ribonucleic acid levels in cultured rat granulosa cells. Endocrinology 130 1296-1302.

Tsukamura H, Yamada S \& Maeda K 2000 Fasting-induced changes in pulsatile luteinizing hormone $(\mathrm{LH})$ secretion in male rats: the role of testosterone and the hypothalamic paraventricular nucleus. Journal of Reproduction and Development 46 227-234.

Received 15 August 2003

First decision 10 October 2003

Accepted 1 December 2003 